\title{
EVALUASI KARAKTERISTIK KRIM EKSTRAK KUNYIT (Curcuma domestica Val.) PADA BERBAGAI FORMULASI
}

\author{
Freddy Marthin Putra Simangunsong ${ }^{1}$, Sri Mulyani ${ }^{2}$, Amna Hartiati ${ }^{2}$ \\ ${ }^{1}$ Mahasiswa Jurusan Teknologi Industri Pertanian, Fakultas Teknologi Pertanian Unud \\ ${ }^{2}$ Dosen Jurusan Teknologi Industri Pertanian, Fakultas Teknologi Pertanian Unud \\ Email :marthinzz.putra@gmail.com ${ }^{1}$ \\ Email koresponden: srimulyani@ unud.ac.id $^{2}$
}

\begin{abstract}
This study aims to: 1) determine the effect of formulations on cream characteristics, 2) determine the formulations that produce the cream with the best characteristics. The experiments using Randomized Block Design consisted of 5 treatments and were grouped into 3. The cream was stored for 6 weeks and observed every 2 weeks, the $6^{\text {th }}$ week data was tested with analysis of variances, followed by Duncan test. The variables observed were homogeneity, separation ratio, dispersion, stickiness, $\mathrm{pH}$, viscosity, antioxidant capacity. The results of the cream research at 6 weeks were: the treatment had an effect on the spread, viscosity, adhesiveness, $\mathrm{pH}$ of cream at 6 weeks, but had no effect on antioxidant activity. During the storage of the cream remains homogeneous and does increase the separation of cream $(\mathrm{F}=1)$, there is an increase in dissolved power and $\mathrm{pH}$ but the adhesion, viscosity, and antioxidant activity decreases. The best results are the first formulation (F1) characteristics: homogeneous creams and no separation $(\mathrm{F}=1), 4,08 \mathrm{~cm}$ spread, $40.758 \mathrm{cp}$ viscosity, 16.2 seconds adhesiveness, IC50 antioxidant activity: $48.39 \mu \mathrm{g} / \mathrm{mL}$ and $\mathrm{pH} 8.17$.
\end{abstract}

Keywords: turmeric extract, stability, cream, formulation, antioxidants, IC50

\section{PENDAHULUAN}

Antioksidan adalah suatu senyawa yang pada konsentrasi rendah secara signifikan dapat menghambat atau mencegah oksidasi substrat dalam reaksi rantai (Halliwell dan Whitemann, 2004; Leong dan Shui, 2002). Antioksidan dapat melindungi sel-sel dari kerusakan yang disebabkan oleh molekul tidak stabil yang dikenal sebagai radikal bebas. Antioksidan dapat mendonorkan elektronnya kepada molekul radikal bebas, sehingga dapat menstabilkan radikal bebas dan menghentikan reaksi berantai. Contoh antioksidan antara lain $\beta$ karoten, likopen, vitamin C, vitamin E (Sies, 1997). Radikal bebas adalah sejenis oksigen yang susunan atomnya tidak sempurna, serta radikal ini cenderung mengadakan reaksi berantai yang apabila terjadi di dalam tubuh akan dapat menimbulkan kerusakan-kerusakan yang berlanjut dan terus menerus (Wahdaningsih, 2011). Radikal bebas merupakan zat berbahaya yang sangat reaktif dan bersifat merusak jaringan organ-organ tubuh hingga menimbulkan berbagai penyakit di usia tua (Sumampouw, 2006).

Kunyit merupakan salah satu sumber antioksidan karena adanya kandungan kurkumin (Purba dan Martosupono, 2009). Ekstrak kunyit berpotensi untuk dijadikan krim karena memiliki kurkumin yang berpotensi sebagai antioksidan, selain itu kunyit juga sudah dikenal sebagai tanaman obat dan mudah didapatkan. Antioksidan kunyit berpotensi dimanfaatkan sebagai pelindung kulit, karena kunyit mengandung komponen antioksidan golongan fenolik (Bengmark, 2006; Arranz dkk., 2010). Penelitian tentang krim antioksidan dari bahan alami sudah banyak dilakukan seperti krim antioksidan ekstrak etanol bawang hutan (Sharon $d k k .$, 2013), krim ekstrak etanol daun lamun (Juwita $d k k ., 2013)$, krim kunyit ekstrak metanol (Alakh $d k k ., 2011)$, krim ekstrak kunyit (Bakkara $d k k, 2017)$. 
Pada penelitian tentang krim ekstrak kunyit yang dilakukan oleh Bakkara dkk (2017), krim yang dihasilkan masih belum memenuhi karakteristik krim yang baik, terutama pada penyebaran krim belum memenuhi standar. Hal ini disebabkan karena kurangnya jumlah air pada formulasi krim. Berdasarkan hal tersebut diatas maka perlu dilakukan penelitian tentang formula krim ekstrak kunyit yang mampu menghasilkan krim yang sesuai dengan karakteristik dan memenuhi SNI. Pada penelitian ini dilakukan formulasi krim dengan jumlah penambahan air yang berbeda-beda, dengan harapan agar krim yang dihasilkan akan sesuai dengan karakteristik dan memenuhi SNI.

\section{METODE PENELITIAN}

\section{Tempat dan Waktu Kegiatan}

Penelitian ini dilakukan di Laboratorium Biokimia dan Nutrisi, Laboratorium Analisis Pangan dan Laboratorium Mikrobiologi Pangan Fakultas Teknologi Pertanian Universitas Udayana.Waktu pelaksanaan penelitian mulai Maret sampai Juni 2017.

\section{Alat dan Bahan}

Peralatan yang digunakan dalam penelitian ini yaitu: timbangan analitik (SHIMADZU), spatula, labu erlenmeyer,beaker glass (Pyrex), oven gas, gelas ukur, batang pengaduk, water bath, $\mathrm{pH}$ meter digital, pipet tetes, pipet mikro, pipet volume, evaporator, sentrifuse, vortex, cawan krim, pengukur suhu ruangan, viskometer (Brookfield engineering Laboratories, Inc), tabung reaksi, batang kaca bengkok (spread), stopwatch, penggaris, spidol, labu takar $(5 \mathrm{~mL}, 10 \mathrm{~mL}$, dan $100 \mathrm{~mL})$, kertas label, aluminium foil, tisu. Bahan yang digunakan dalam penelitian ini terdiri dari kunyit, etanol 96\% (brataco), asam stearat (SAP Chemicals), triethanolamine (TEA), VCO (Sudamala), mineral oil (Sigma-Aldrich), moisturizer conditioner (propilen glikol, gliserol, sorbitol) (SAP Chemicals), setil alkohol (SAP Chemicals), metil paraben (SAP Chemicals), propil paraben (SAP Chemicals), sodium metabesulfite, EDTA, akuades, metanol, asam galat, DPPH.

\section{Rancangan Percobaan}

Percobaan menggunakan Rancangan Acak Kelompok (RAK). Percobaan ini terdiri dari 5 perlakuan formulasi dan perlakuan dikelompokkan menjadi 3, sehingga diperoleh 15 unit percobaan disimpan dalam 6 minggu. Percobaan diamati setiap 2 minggu sekali dengan penyimpanan 6 minggu sehingga diperoleh 60 unit percobaan. Data minggu ke-6 diuji dengan sidik ragam, apabila perlakuan berpengaruh dilanjutkan uji Duncan.

\section{Pelaksanaan Penelitian}

Penelitian ini dilakukan dengan 3 tahap, yaitu : tahapan penyiapan ekstrak kunyit, tahapan pembuatan krim ekstrak kunyit dan tahapan pengujian sediaan krim ekstrak kunyit.

Tahap 1 : Penyiapan ekstrak kunyit

Rimpang kunyit yang telah diperoleh dari daerah Petang, kabupaten Badung berumur panen 11 bulan, dicuci sampai bersih, kemudian ditiriskan sampai kering. Selanjutnya kunyit diiris dengan ketebalan sekitar $0,1 \mathrm{~cm}$, kemudian dilakukan pengeringan dengan oven pada suhu tidak lebih dari $55^{\circ} \mathrm{C}$ sampai mencapai kadar air maksimal 10\%. Simplisia kunyit dibuat menjadi bubuk dengan ukuran 80 mesh. Selanjutnya $200 \mathrm{~g}$ bubuk kunyit diekstrak dengan pelarut etanol 96\% dengan metode maserasi dengan rasio bahan : pelarut (1:6). Maserasi tahap pertama dilakukan selama 24 jam dengan dua kali pengadukan yang masing masing diaduk 
setiap 12 jam sekali. Selanjutnya setelah 24 jam dilakukan penyaringan menggunakan kertas whatman no.1, penyaringan dilakukan untuk memisahkan anatara ampas dengan filtrat. Setelah dimaserasi, filtrat yang di dapat diuapkan menggunakan evaporator. Hasil evaporasi yang diperoleh merupakan ekstrak kunyit yang digunakan sebagai bahan aktif yang ditambahkan pada krim untuk penelitian ini. (Mulyani, $d k k$. 2016).

Tahap 2 : Pembuatan krim

Setelah hasil ekstrak kunyit diperoleh, selanjutnya adalah proses pembuatan krim. Formula krim ekstrak kunyit yang digunakan dalam penelitian ini seperti yang ditunjukkan pada Tabel 1.

Tabel 1. Formula krim ekstrak kunyit

\begin{tabular}{|c|c|c|c|c|c|c|}
\hline \multirow[b]{2}{*}{ No } & \multirow[b]{2}{*}{ Jenis bahan } & \multicolumn{5}{|c|}{ Formula (berat/berat) } \\
\hline & & F0 & F1 & F2 & $\mathrm{F} 3$ & F4 \\
\hline 1 & Ekstrak kunyit & 0,1 & 0,15 & 0,15 & 0,15 & 0,15 \\
\hline 2 & Asam stearat & 6 & 5,45 & 5 & 4,6 & 3,9 \\
\hline 3 & Triethanolamine & 0,8 & 0,75 & 0,65 & 0,6 & 0,55 \\
\hline 4 & Minyak almond /VCO & 2 & 2 & 2 & 2 & 2 \\
\hline 5 & Mineral oil & 1,25 & 1,15 & 1,05 & 0,95 & 0,8 \\
\hline 6 & Moisturizer conditioner & & & & & \\
\hline- & Propilen Glikol (6\%) & 3 & 3 & 2,75 & 2,5 & 2,25 \\
\hline- & Gliserin $(3 \%)$ & 1,5 & 1,5 & 1,35 & 1,25 & 1,35 \\
\hline- & Sorbitol (3\%) & 1,5 & 1,5 & 1,35 & 1,25 & 1,35 \\
\hline 7 & Setyl alcohol & 0,5 & 0,45 & 0,4 & 0,4 & 0,3 \\
\hline 8 & Methyl paraben & 0,09 & 0,1 & 0,1 & 0,05 & 0,05 \\
\hline 9 & Propyl paraben & 0,01 & 0,01 & 0,01 & 0,01 & 0,01 \\
\hline 10 & Sodium metabsisulfite & 0,05 & 0,05 & 0,05 & 0,05 & 0,05 \\
\hline 11 & EDTA & 0,05 & 0,05 & 0,05 & 0,05 & 0,05 \\
\hline 12 & Air & 32,25 & 33,1 & 34,2 & 35,3 & 36,9 \\
\hline
\end{tabular}

Sumber: Bakkara (modifikasi) $d k k .2017$

Dalam pembuatan emulsi terdapat dua fase, yaitu fase minyak dan fase air (Swastika, 2013). Fase minyak terdiri dari asam stearat, mineral oil, $\mathrm{VCO}$, setil alkohol dan fase air yaitu water (aquades), triethanolamine, moisturizer conditioner. Ekstrak kunyit dimasukkan ke dalam fase minyak. Fase minyak dan air dipanaskan pada suhu $55^{\circ} \mathrm{C}$ dengan water bath secara terpisah. Pemanasan dilakukan sampai seluruh komponen penyusun krim pada fase minyak melebur dan fase air melarut dengan adanya pengadukan. Selanjutnya campuran fase air ditambahkan ke dalam campuran fase minyak sambil diaduk secara konstan hingga homogen dan terjadi penurunan suhu. Diagram alir proses pembuatan krim ekstrak kunyit dapat dilihat pada gambar 9 .

Tahap 3 : Pengujian krim

Krim esktrak kunyit yang diperoleh dilakukan analisis meliputi uji krim yaitu, uji daya sebar, uji viskositas, uji daya lekat, uji $\mathrm{pH}$, dan uji rasio pemisahan krim serta uji aktivitas antioksidan dengan metode $\mathrm{IC}_{50}$. Analisis dilakukan setiap 2 minggu sekali, dimulai pada minggu ke-0 hingga 6 minggu penyimpanan. Data yang diperoleh akan dilakukan analisis lanjutan untuk mendapatkan regresi. 


\section{HASIL DAN PEMBAHASAN}

\section{Daya Sebar}

Hasil pengujian daya sebar emulsi ekstrak kunyit, disajikan pada Gambar 1. Hasil pengujian menunjukkan daya sebar pada minggu ke-0 berada pada kisaran $3,31 \mathrm{~cm}-4,63 \mathrm{~cm}$ dan pada minggu ke 6 berada pada kisaran $4,08 \mathrm{~cm}-5,36 \mathrm{~cm}$. Spesifikasi diameter daya sebar yang diharapkan yaitu antara $5-7 \mathrm{~cm}$ (Garg $d k k, 2001$ ). Hasil menunjukkan bahwa daya sebar emulsi semakin meningkat tiap minggunya. Daya sebar yang meningkat disebabkan karena meningkatnya jumlah air pada tiap formula. Ketidakcukupan emulsifier dalam sistem emulsi akan menyebabkan terjadinya pemisahan fase. Jumlah air dalam formula pada penelitian ini meningkat, sementara emulsifier nya menurun, sehingga menyebabkan emulsi tidak stabil dan daya sebar meningkat.

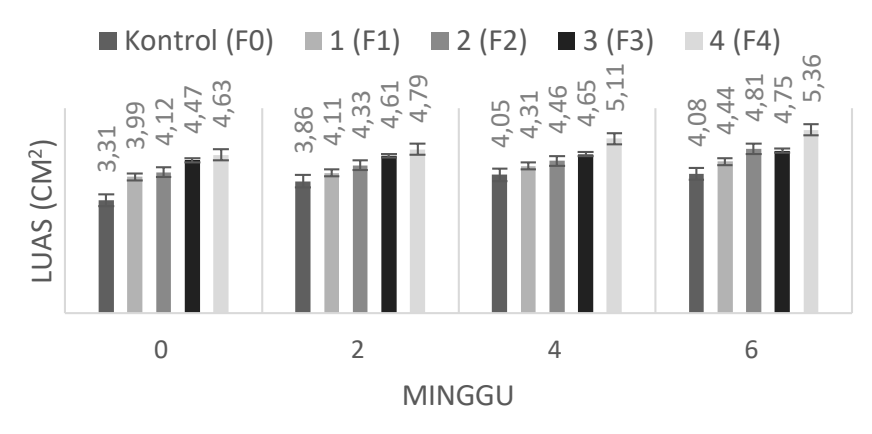

Gambar 1. Grafik daya sebar krim selama penyimpanan 6 minggu, rata-rata \pm SD $(n=3)$

Daya sebar yang baik menyebabkan kontak antara emulsi dengan kulit menjadi luas, sehingga absorpsi emulsi ke kulit berlangsung cepat (Voigt, 1984).Hasil pengujian daya sebar emulsi ekstrak kunyit minggu ke-6, disajikan pada Tabel 2.

Tabel 2. Daya sebar krim pada pengamatan minggu ke-6 penyimpanan

\begin{tabular}{cc}
\hline Formula & $\mathrm{cm}$ \\
\hline Kontrol (F0) & $\left.4,08 \mathrm{e}^{*}\right)$ \\
Formulasi 1 (F1) & $4,44 \mathrm{~d}$ \\
Formulasi 2 (F2) & $4,8 \mathrm{~b}$ \\
Formulasi 3 (F3) & $4,75 \mathrm{bc}$ \\
Formulasi 4 (F4) & $5,36 \mathrm{a}$ \\
\hline
\end{tabular}

Keterangan: *)Huruf yang berbeda di belakang nilai rata-rata menunjukan ada beda nyata pada taraf kepercayaan $5 \%$

Berdasarkan Tabel 2, hasil uji Duncan menunjukkan bahwa sampai minggu ke-6 perlakuan formulasi emulsi berpengaruh nyata terhadap daya sebar. Hal ini disebabkan karena penambahan air dalam formulasi emulsi rata-rata $1,16 \mathrm{~mL}$ dalam $50 \mathrm{~g}$ emulsi $(2,3 \%)$ sehingga menyebabkan daya sebar berbeda.

\section{Viskositas}

Viskositas yang baik akan mempunyai nilai yang tinggi karena semakin tinggi viskositas suatu bahan maka pergerakan partikel akan cenderung makin sulit sehingga bahan akan semakin stabil (Schmitt, 1996). 


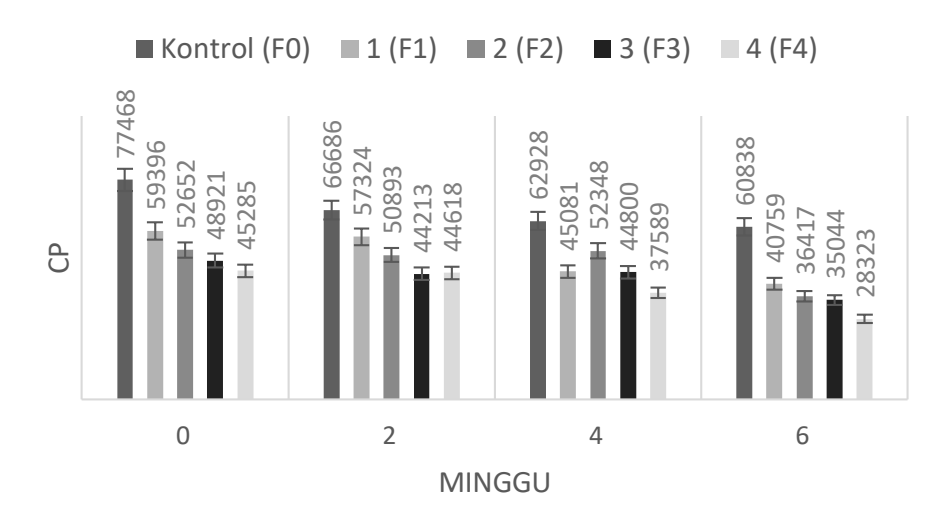

Gambar 2. Grafik uji viskositas krim selama penyimpanan 6 minggu pada rpm 5 dan suhu $27^{\circ} \mathrm{C}$,

$$
\text { rata-rata } \pm \operatorname{SD}(n=3)
$$

Hasil pengujian viskositas pada minggu ke-0 berada pada kisaran $77.468 \mathrm{cp}-45.285 \mathrm{cp}$ dan minggu ke-6 kisaran $60.838-28.323 \mathrm{cp}$

Berdasarkan Gambar 2 tersebut menunjukkan terjadinya penurunan viskositas emulsi selama penyimpanan. Penurunan viskositas dapat dipengaruhi beberapa hal seperti pencampuran, pengadukan, pemilihan surfaktan, emulgator dan proporsi fase terdispersi (Alfred $d k k ., 1993$ ). Viskositas yang menurun disebabkan karena meningkatnya jumlah air pada tiap formula, dan emulsifier jumlahnya menurun.Pada tabel, dapat dilihat bahwa viskositas emulsi semakin naik dengan semakin meningkatnya kandungan jumlah air yang ditambahkan dalam emulsi (Gambar 2). Hasil sediaan menunjukkan sediaan emulsi masih memenuhi syarat sediaan emulsi SNI 16-4399-1996 yaitu berada dalam kisaran nilai 2.000-50.000 cp (centipoise)

Tabel 3. Viskositas krim pada pengamatan minggu ke-6 penyimpanan

\begin{tabular}{cc}
\hline Formula & Viskositas (cp) \\
\hline Kontrol (F0) & $60.838,2 \mathrm{a}^{*}$ \\
Formulasi 1 (F1) & $40.758,63 \mathrm{~b}$ \\
Formulasi 2 (F2) & $36.416,58 \mathrm{c}$ \\
Formulasi 3 (F3) & $35.044,17 \mathrm{~d}$ \\
Formulasi 4 (F4) & $28.322,79 \mathrm{e}$ \\
\hline
\end{tabular}

Keterangan: $\left.{ }^{*}\right)$ Huruf yang berbeda di belakang nilai rata rata menunjukan ada beda nyata pada taraf kepercayaan $5 \%$

Tabel 3 menunjukkan perlakuan formula berpengaruh nyata terhadap viskositas pada minggu ke-3.Hal ini disebabkan karena dengan meningkatnya jumlah air pada formula, kandungan TEA dan asam stearat berkurang.TEA dan asam stearat berfungsi sebagai emulsifier, sehingga semakin berkurangnya emulsifier, maka viskositas emulsi juga berkurang.

\section{Daya Waktu Lekat}

Uji daya waktu lekat bertujuan mengetahui kemampuan emulsi untuk melekat atau menempelnya pada permukaan kulit pada saat digunakan. Semakin lama emulsi melekat pada kulit, maka zat aktif yang dilepaskan dari basis akan semakin banyak diabsorsi. 
Hasil pengujian daya waktu lekat emulsi ekstrak kunyit disajikan pada Gambar 3. Hasil pengujian menunjukkan daya lekat emulsi ekstrak kunyit pada minggu ke-0 berada pada kisaran28,9-18,36 detik, dan pada minggu ke-6 berada pada kisaran 14, -27,03 detik. Hasil uji menunjukkan bahwa daya lekat cenderung meningkat. Peningkatan daya lekat ini disebabkan karena viskositas emulsi yang juga cenderung meningkat. Hal tersebut sesuai dengan hasil pengujian viskositas emulsi ekstrak kunyit yang mengalami peningkatan (Gambar 3), yang artinya tingkat kekentalan emulsi semakin meningkat selama 6 minggu penyimpanan, dimana daya lekat emulsi berbanding lurus dengan viskositas. Hal ini didukung dengan penelitian Windriyati, 2007 mengatakan bahwa penurunan daya lekat dipengaruhi oleh banyaknya kandungan air dalam emulsi. Semakin lama emulsi melekat pada kulit maka efek yang ditimbulkan juga semakin besar (Nabilah, $d k k$. 2014), hasil pengujian daya lekat, didapatkan diagram pengujian daya lekat emulsi ekstrak kunyit minggu ke-6 disajikan pada Tabel 4.

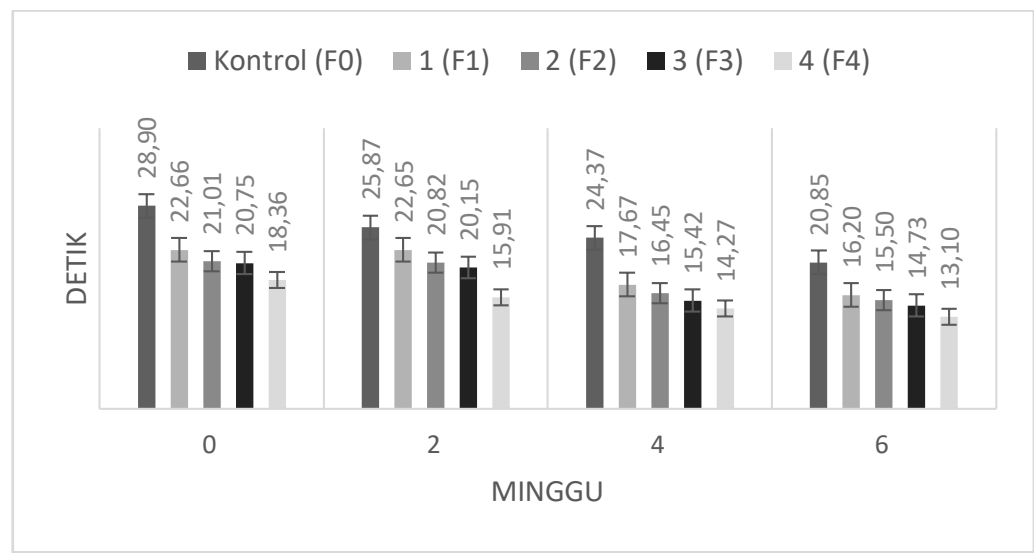

Gambar 3. Grafik uji daya lekat selama penyimpanan 6 minggu, rata-rata \pm SD $(n=3)$

Tabel 4.Daya lekat krim pada pengamatan minggu ke-6 penyimpanan

\begin{tabular}{cc}
\hline Formula & detik \\
\hline Kontrol (F0) & $20.85 \mathrm{a}^{*}$ \\
Formulasi 1 (F1) & $16,20 \mathrm{~b}$ \\
Formulasi 2 (F2) & $15.50 \mathrm{c}$ \\
Formulasi 3 (F3) & $14,73 \mathrm{~d}$ \\
Formulasi 4 (F4) & $13.10 \mathrm{e}$
\end{tabular}

Keterangan: *) Huruf yang berbeda di belakang nilai rata rata menunjukan ada beda nyata pada taraf kepercayaan $5 \%$

Tabel 4 menunjukkan bahwa sampai minggu ke-6 perlakuan formulasi emulsi berpengaruh sangat nyata terhadap daya sebar. Hal ini disebabkan karena dalam formula dengan meningkatnya jumlah air, kandungan TEA dan asam stearat berkurang. Pada emulsi, TEA dan asam stearat berfungsi sebagai emulsifier, sehingga semakin berkurangnya emulsifier dan bertambahnya jumlah air, maka viskositas emulsi juga berkurang. Viskositas berbanding lurus dengan daya lekat, sehingga viskositas berkurang maka daya lekat berkurang.

\section{4. $\mathrm{pH}$}

Uji pH bertujuan untuk mengetahui tingkat keasaman atau kebasaan dari emulsi yang dihasilkan. Emulsi yang baik digunakan pada kulit adalah emulsi yang memilki nilai $\mathrm{pH}$ yaitu 4,5-6,5 agar tidak menyebabkan iritasi kulit dan nyaman digunakan (Tranggono dan Latifah, 2007). 
Hasil pengujian pH emulsi ekstrak kunyit disajikan pada Gambar 4. Hasil pengujian menunjukkan bahwa kisaran $\mathrm{pH}$ pada minggu ke-0 sebelum penyimpanan berada pada 7,56-7,83 dan minggu ke-6 pada 8,16-8,34. Grafik tersebut menunjukkanbahwa $\mathrm{pH}$ mengalami kenaikan pada tiap minggunya. $\mathrm{pH}$ yang meningkat disebabkan oleh emulsi yang tidak stabil. Emulsi tidak stabil disebabkan karena selama penyimpanan trietanolamin lepas. Trietanolamin bersifat basa kuat sehingga meningkatkan pH pada emulsi.

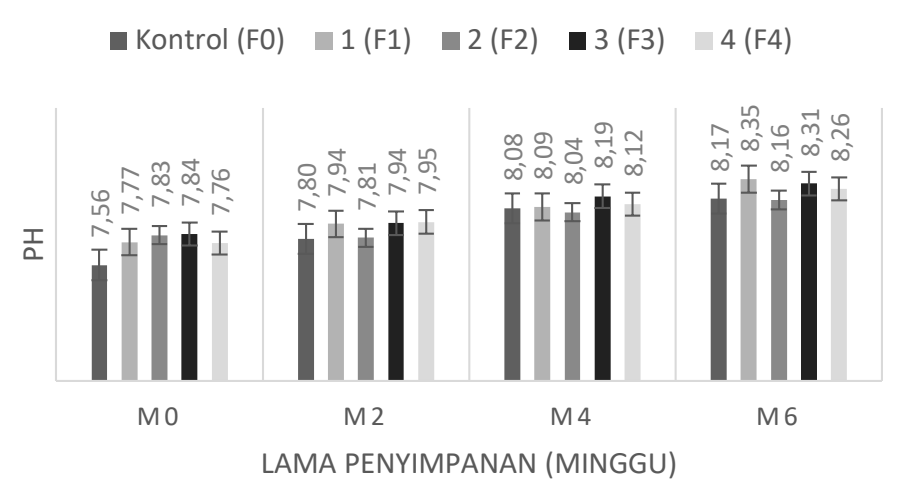

Gambar 4. Grafik uji pH krim selama penyimpanan 6 minggu, rata-rata \pm SD $(n=3)$

Perubahan $\mathrm{pH}$ juga disebabkan faktor lingkungan seperti suhu, penyimpanan yang kurang baik, kombinasi ekstrak yang kurang stabil dalam sediaan karena teroksidasi (Young $d k k$ 2002).

\begin{tabular}{cc} 
Tabel 5.pH krimpada pengamatan minggu ke-6 penyimpanan \\
\hline Formula & $\mathrm{pH}$ \\
\hline Kontrol (F0) & $8,23 \pm 0,14 \mathrm{a}^{*}$ \\
Formulasi 1 (F1) & $8,35 \pm 0,21 \mathrm{a}$ \\
Formulasi 2 (F2) & $8,12 \pm 0,06 \mathrm{a}$ \\
Formulasi 3 (F3) & $8,13 \pm 0,27 \mathrm{a}$ \\
Formulasi 4 (F4) & $8,18 \pm 0,15 \mathrm{a}$ \\
\hline
\end{tabular}

Keterangan: *) Rata rata \pm standar deviasi; $\mathrm{n}=3$, huruf yang sama di belakang rata rata menunjukan tidak ada beda nyata pada taraf kepercayaan $5 \%$

Tabel 5 menunjukkan, formula tidak berpengaruh nyata terhadap terhadap pH karena penambahan bahan pengawet pada masing-masing formula tidak terlalu banyak. Secara keseluruhan kondisi $\mathrm{pH}$ bersifat netral selama penyimpanan 6 minggu. Hal ini disebabkan karena adanya kombinasi kadar asam stearat dan trietanolamine yang mempengaruhi $\mathrm{pH}$ emulsi. Trietanolamine yang memiliki $\mathrm{pH}$ sebesar 10,5 (Rowe $d k k$, 2009) dimana $\mathrm{pH}$ tersebut menunjukkan basa kuat. Sehingga TEA diduga menjadi pembawa basa pada $\mathrm{pH}$ sediaan emulsi ekstrak kunyit ini. Akan tetapi nilai pH emulsi tidak menjadi basa karena adanya komponen penyusun emulsi lainnya, seperti asam sterat. Sediaan emulsi yang memiliki nilai $\mathrm{pH}$ yang kurang dari 4,5 dapat mengiritasi kulit, sedangkan nilai pH yang melebihi 6,5 dapat membuat kulit menjadi bersisik (Sharon, $d k k ., 2013)$.

\section{Uji Homogenitas}

Uji homogenitas bertujuan untuk mengetahui karakteristik dan pemerataan pencampuran komponenkomponen yang ada pada sediaan krim. Pengamatan dilakukan dari minggu ke-0 hingga minggu ke-6. Hasil pengamatan uji homogenitas menunjukkan bahwa seluruh sediaan krim ekstrak kunyit homogen. Krim homogen 
ditandai dengan penyebaran warna dan pencampuran sediaan krim yang merata serta tidak adanya butiran-butiran kasar (Lubis, 2012).. Hal tersebut sesuai dengan persyaratan sediaan krim, dimana harus menunjukkan susunan yang homogen dan tidak terlihatnya butiran-butiran kasar (Lubis, 2012). Sediaan krim yang homogen mengindikasikan bahwa bahan-bahan yang digunakan dalam pembuatan krim tercampur sempurna. Suatu sediaan krim harus homogen dan terdistribusi merata agar tidak menyebabkan iritasi ketika dioleskan pada permukaan kulit.

\section{Uji Rasio Pemisahan Krim}

Uji rasio pemisahan krim dengan metode setrifugasi bertujuan untuk memisahkan dua atau lebih zat yang memiliki kepadatan yang berbeda seperti dua cairan yang berbeda atau cairan padatan karena adanya pengaruh gaya sentrifugal dan merupakan suatu alat yang berguna untuk menilai dan memprediksi shelf-life suatu emulsi (Khan, et al., 2010). Pengujian ini dilakukan dengan cara mengamati perbandingan antara tinggi fase krim yang memisah dengan tinggi emulsi mula-mula. Emulsi dikatakan stabil jika nilai rasio pemisahan=1 yang artinya bahwa emulsi tidak pecah atau memisah. Hasil pengujian yang diperoleh dari seluruh krim tidak adanya pemisahan emulsi dari sebelum penyimpanan hingga minggu ke-6, dan memiliki nilai rasio pemisahan=1.

Hal tersebut diduga karena penggunaan kombinasi emulgator asam stearat dan trietanolamin. Zat pengemulsi atau emulgator berperan penting untuk menciptakan krim yang stabil. Emulgator bekerja dengan membentuk lapisan (film) disekeliling tetesan terdispersi sehingga mencegah terjadinya koalesen dan terpisahnya cairan dispersi (Anief, 2008). Kecepatan pengadukan yang sesuai juga berpengaruh selama proses homogenisasi krim yang mencegah terjadinya pemisahan selama pengujian (Smaoui, $d k k ., 2013$ ).

\section{Aktivitas Antioksidan}

Uji aktivitas krim dilakukan dengan $\mathrm{IC}_{50}$, nilai $\mathrm{IC}_{50}$ adalah konsentrasi ekstrak yang dapat menurunkan 50\% intensitas serapan (Mulja dan Suharman, 1995). IC $_{50}$ terhadap radikal bebas DPPH, bertujuan untuk mengetahui konsentrasi sediaan yang dapat menghambat 50\% radikal bebas DPPH. Sediaan krim diharapkan memiliki kemampuan menyerap radikal bebas dengan cukup baik sehingga dapat mencegah kerusakan kulit yang ditimbulkan sinar UV A dan UV B. Hasil pengujian $\mathrm{IC}_{50}$ krim terhadap radikal bebas DPPH disajikan pada Gambar 5.

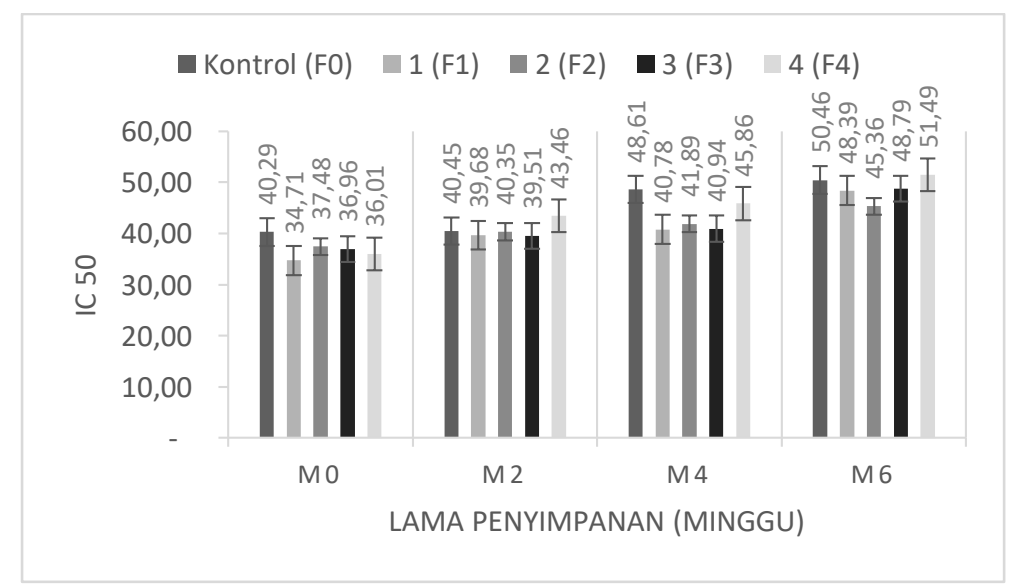

Gambar 5. Grafik analisis aktivitas antioksidan krim dengan $\mathrm{IC}_{50}$ selama penyimpanan 6 minggu, rata-rata $\pm \mathrm{SD}$ $(n=3)$ 
Hasil menunjukan $\mathrm{IC}_{50}$ sediaan mengalami peningkatan tiap minggunya yang menandakan menurunnya aktivitas antioksidan pada krim. Adanya penurunan aktivitas antioksidan tersebut mungkin karena dalam formula krim tidak ditambahkan antioksidan tambahan sehingga konsentrasi ekstrak dalam krim berperan sebagai antioksidan untuk melindungi krim (Budiman, 2008). Peningkatan angka pada $\mathrm{IC}_{50}$ menandakan bahwa semakin berkurang aktifitas antioksidan krim dalam menghambat radikal bebas. Namun hasil masih menunjukkan aktivitas antioksidan krim ekstrak kunyit masih sangat kuat karena nilai $\mathrm{IC}_{50}$ lebih kecil dari 50ppm.

Tabel 6. Aktivitas Antioksidan krim dengan $\mathrm{IC}_{50}$ pada pengamatan minggu ke-6 penyimpanan

\begin{tabular}{cc}
\hline Formula & $\mathrm{IC}_{50}$ \\
\hline Kontrol (F0) & $\left.50.46 \pm 2,28 \mathrm{a}^{*}\right)$ \\
Formulasi 1 (F1) & $48,39 \pm 2,37 \mathrm{a}$ \\
Formulasi 2 (F2) & $45,36 \pm 1,56 \mathrm{a}$ \\
Formulasi 3 (F3) & $48,79 \pm 1,7 \mathrm{a}$ \\
Formulasi 4 (F4) & $51,49 \pm 0,5 \mathrm{a}$ \\
\hline
\end{tabular}

Keterangan: *) Huruf yang sama di belakang nilai rata rata menunjukan tidak ada beda nyata pada taraf kepercayaan $5 \%$

Berdasarkan Tabel 6, hasil uji Duncan menunjukan bahwa formula tidak berpengaruh nyata terhadap terhadap $\mathrm{IC}_{50}$ karena jumlah ekstrak yang ditambahkan tidak berbeda pada tiap formulasinya, sementara jumlah air pada formulasi bertambah yang menyebabkan antioksidan pada ekstrak cepat rusak. Hasil menunjukan bahwa sediaan krim ekstrak kunyit pada minggu ke-6 mempunyai aktivitas antioksidan yang masihkuat karena mempunyai $\mathrm{IC}_{50}$ kurang dari $200 \mu \mathrm{g} / \mathrm{mL}$ (Blouis,1958).

\section{KESIMPULAN DAN SARAN}

\section{Kesimpulan}

1. a. Daya sebar dan pH mengalami peningkatan; daya lekat, viskositas, dan aktivitas antioksidan mengalami penurunan selama 6 minggu penyimpanan, namun krim tetap homogen dan tidak terjadi pemisahan krim (F =1) selama 6 minggu penyimpanan.

b. Formulasi bahan berpengaruh terhadap daya sebar, viskositas, daya lekat, $\mathrm{pH}$ krim pada minggu ke-6, tetapi formulasi bahan tidak berpengaruh terhadap aktivitas antioksidan sampai minggu ke-6.

2. Formulasi terbaik sampai minggu ke-6 yaitu pada formulasi pertama (F1) dengan karakteristik sebagai berikut: daya sebar 4,08 cm, viskositas $40.758 \mathrm{cP}$, daya lekat 16,2 detik, aktivitas antioksidan $\mathrm{IC}_{50}: 48,39 \mu \mathrm{g} / \mathrm{mL}, \mathrm{pH}$ 8,17 , krim homogen dan rasio pemisahan $(\mathrm{F}=1)$.

\section{Saran}

Perlu dilakukan penelitian lebih lanjut tentang konsentrasi ekstrak kunyit yang mampu menghasilkan pH dan daya sebar yang stabil serta memenuhi standar. 


\section{DAFTAR PUSTAKA}

Badan Standarisasi Nasional. 1996. Sediaan Tabir Surya. Standar Nasional Indonesia. Jakarta.

Bakkara, A. 2016. Stabilitas Emulsi Krim Ekstrak Kunyit (Curcuma domestica Val.) Pada Berbagai Konsentrasi. Skripsi. Fakultas Teknologi Pertanian, Udayana, Bali.

Bakkara A, Satriawan IK, dan Sri Mulyani. 2017. Stability of Emulsion Cream Extract Turmeric (Curcuma domestica Val.) in Various Concentration. Journal of Biology, Agriculture and Healthcare. 7 : 93 99.

Budiman, M.H. 2008. Uji stabilitas fisik dan aktivitas antioksidan sediaan krim yang mengandung ekstrak kering tomat (Solanum lycopersicum L.). Skripsi. Departemen Farmasi, Fakultas Matematika dan Ilmu Pengetahuan Alam, UI, Depok.

Depkes RI. 1995. Farmakope Indonesia, Edisi IV, Departemen Kesehatan Republik Indonesia, Jakarta.

Depkes RI. 2000. Inventaris Tanaman Obat Indonesia (I). Jilid II. Jakarta: Departemen Kesehatan RI dan Kesejahteraan Sosial RI Badan Penelitian dan Pengembangan Kesehatan. Halaman 163-164.

Draelos, Z.D. \& Lauren, A.T., 2006, Cosmetic Formulation of Skin Care Products, 234-235, Taylor dan Francis Group, New York.

Gandjar, G.H., dan Rohman, A., (2007). Kimia Farmasi Analisis. Pustaka Pelajar: Yogyakarta: hal.120, 164, 166.

Garg, A., Aggarwal, D., Garg, S., Singla, A.K., 2002.Spreading of Semisolid Formulation.Pharmaceutical Technology.

Govindarajan, V.S., (1980), Turmeric-Chemistry, Technology and Quality, Food SciNutr., 12, pp. 199-301.

Han, K.H., et al. 2007. Effects of Anthocyanin-Rich Purple Potato Flakes on Antioxidant Status in F344 Rats Fed a Cholesterol-Rich Diet. BritishJournal of Nutrition (2007), 98, 914-921 doi:10.1017/S0007114507761792 @The Authors 2007.

Hugo, W.B. and A. D. Russel. (1981). Pharmaceutical Microbiology. Blackwell Scientific Publication. Oxford.

Huhtanen, C.N. 1980. "Inhibition of clostridium botulimum by spice extracts and aliphatic alcohols".Journal Of Food Protect. 43(3) : 195

Iswindari, D.2014. Formulasi dan Uji Aktivitas Antioksidan Krim Rice Bran Oil. Fakultas Kedokteran dan Ilmu Kesehatan, UIN, Jakarta.

Juwita, Anisa Puspa., Yamlean, Paulina V.Y., dan Edy, Hosea Jaya. "Formulasi Krim Ekstrak Etanol Daun Lamun (Syringodium isoetifolium)". Jurnal Ilmiah Farmasi-UNSRAT. 2013; 2(2): 8-12.

Khan, B.A., Akhtar, N., Mahmood, T., Qayum, M, Zaman, S.U. 2010. Formulation and Pharmaceutical Evaluation of a W/O Emulsion of Hippophae Ramnoides Fruit Extract. J. Pharm. Res. 3 : 1342-1344.

Lachman L., Herbert, A. L. \& Joseph, L. K., 2008, Teori dan Praktek Industri Farmasi Edisi III, 1119-1120, Penerbit Universitas Indonesia, Jakarta.

Martin, A., Swarbrick, J., Cammarata, A. 1993. Farmasi Fisik: Dasar - dasar Kimia Fisik dalam Ilmu Farmasetik. Edisi ke-3. UI PRESS, Jakarta.

Michael dan Ash, I., 1997.A Formulary of Cosmetic Preparation, Chemical Publishing Co., New York.

Minanti, R. 2016. Studi Kapasitas Antioksidan Pada Ekstrak Kunyit dan Daun Asam.Skripsi.Fakultas Teknologi Pertanian, UNUD, Bali. 
Mitsui,T.1997.New Cosmetic Science. Tokyo : Shiseido Co., Ltd.

Mulyani, S., B. Admadi. H, N. S. Antara, I. N. K. Putra, 2016. An Assessment of Antioxidant Characteristics from different ratios Of Turmeric and Tamarind (Curcuma domestica Val.Tamarindus indica L.) Leaves extracts. Australian Journal of Basic and Applied Sciences,ISSN:1991-8178, EISSN: 2309-8414 (Online) Vol. 10(14) September 2016, Pages: $347-$ 353 (Cited 2017 Oct. 22). Available atwww.ajbasweb.com/old/ajbas/2016/September/347-353.pdf

Pelczar, M.J., R.D. Reid. 1972. "Microbiology”. Mc Graw Hill Book Company, New York.

Purwanto, Mufrod dan Swastika, A.2013.Aktivitas Antioksidan Krim Ekstrak Sari Tomat (Solanum lycopersicum L.), Traditional MedicineJournal, 18(3): 132-140.

Rowe, C.R., Sheskey, P.J., dan Quinn, M.E. (ed), 2009, Handbook of Pharmaceutical Excipients 6th ed., Pharmaceutical Press, London.

Samsundari, S. 2006. Pengujian Ekstrak Temulawak dan Kunyit Terhadap Resistensi Bakteri Aeromonas hydrophila yang Menyerang Ikan Mas (Cyprinus carpio). Jurnal GAMMA. Vol II No 1 : 71-83.

Schneider, Gunther and A.G., Beiersdorf. 2012. Skin Cosmetics, Encyclopedia of Industrial Chemistry, Germany, Federal Republic.

Sharon, N., Anam, S dan Yuliet. 2013. Formulasi Krim Antioksidan Ekstrak Etanol Bawang Hutan (Eleutherine palmifolia L. Merr). Program Studi Farmasi, Fakultas MIPA, Universitas Tadulako. Online Journal of Natural Science, 2(3): 111-122.

Singh, M., Sharma, S., Khokra, S. L., Sahu, R. K., and Jangde, R., 2011, Preparation and Evaluation of Herbal Cosmetic Cream, India, pp 1258 - 1264.

Smaoui, S., Hilma, H. B., Jarraya, R, Kamoun, N. G., Ellouze, R, Damak, M. 2012. Cosmetic Emulsion of Virgin Coconut Oil: Formulation and Biophysical Evaluation. African Journal of Biotechnology Vol 11(40), pp. 9664-9671.

Stahl, E., 1985, Analisis Obat Secara kromatografi dan Mikroskopi, diterjemahkan oleh Kosasih Padmawinata dan Iwang Soediro, 3-17, ITB, Bandung.

Swastika, A. NSP., Mufrod., Purwanto. 2013. Antiokxidant Activity of Cream Dosage Form of Tomato Extract (Solanum lycopersicum L.), Faculty of Pharmacy, University Gadjah Mada, Yogyakarta.

Syah, A.N.A. (2005). Virgin Coconut Oil. Cetakan Kedua. Agromedia Pustaka., Jakarta. Hal. 8.

Tranggono, R. I, Latifah, F. 2007.Buku Pegangan Ilmu Pengetahuan kosmetik.PT. Gramedia, Jakarta.

Voight Rudolf. 1994. Buku Pelajaran Teknologi Farmasi. Gadjah Mada University Press, Yogyakarta.

Winarto, W.P. 2003. Khasiat dan Manfaat Kunyit. Agromedia Pustaka. Jakarta.

Young, Anne. 2002.Practical Cosmetic Science, 39 - 40, Mills and Boon Limited, London. 